(2) Open Access Full Text Article

\title{
Letter to the editor regarding "Study design of 'Friends for Life': a process and effect evaluation of an indicated school-based prevention program": response to Lima et al
}

\author{
This article was published in the following Dove Press journal: \\ Neuropsychiatric Disease and Treatment \\ 23 April 2014 \\ Number of times this article has been viewed
}

\author{
Mia P Kösters' \\ Mai JM Chinapaw ${ }^{2}$ \\ Marieke Zwaanswijk ${ }^{3}$ \\ Marcel $F$ van der Wal' \\ Hans M Koot ${ }^{4,5}$ \\ 'Department of Epidemiology and \\ Health Promotion, Public Health \\ Service of Amsterdam (GGD), \\ Amsterdam, ${ }^{2}$ Department of \\ Public and Occupational Health, \\ EMGO Institute for Health and \\ Care Research, VU University \\ Medical Centre, Amsterdam, \\ ${ }^{3}$ NIVEL, Netherlands Institute for \\ Health Services Research, Utrecht, \\ ${ }^{4}$ Department of Developmental \\ Psychology, Faculty of Psychology and \\ Education, VU University, Amsterdam, \\ ${ }^{5}$ EMGO Institute for Health and Care \\ Research, VU University Medical \\ Centre, Amsterdam, The Netherlands
}

\section{Dear editor}

We would like to respond to the paper "Childhood depression: a systematic review", recently published in Neuropsychiatric Disease and Treatment by Lima et al. ${ }^{1}$ The aforementioned paper presents a systematic review of childhood depression and refers several times to our paper, "Study design of 'FRIENDS for Life': a process and effect evaluation of an indicated school-based prevention programme for childhood anxiety and depression", published in BMC Public Health by Kösters et al. ${ }^{2}$ Unfortunately we noted a number of erroneous statements about our paper. We will address these in order of appearance.

\section{Introduction}

1. In the sentence "However, cases of depressive disorders have increased not only among adults, but also among children"1 (p 1417) reference is made to our study. Our paper describes the design of our study, not the results and therefore includes no evidence that cases of depression are increasing among children.

2. In the sentence "In the short-term, depressive disorders might be a source of psychological suffering for these children, whereas in the long-term they can compromise social, cognitive, and emotional aspects of child development, [...] becoming an important predictor of psychopathologies in adulthood"1 (p 1418) reference is made to our study. Again, we wrote a study design paper, thus no results regarding predictors of psychopathology in adulthood.

\section{Results}

3. In the results section, our study is listed as an "experimental [study]"1 (p 1419). However, as we did not randomize the participants or schools, we conducted a quasi-experimental study.

4. In Table 1 of Lima et al ( 1 1420), our sample is defined as " 20 primary schools". However, when we wrote the study design paper, our sample was not yet definitive. That is the reason that we wrote in our paper, "At least 20 primary schools in Amsterdam planned to participate in 'FRIENDS for Life' in school year 2010/2011 and/or 2011/2012"2 (p 2).

5. In addition, Table 1 ( $p$ 1420) states that we found that 'FRIENDS for Life' is effective as an indicated school-based prevention program. ${ }^{1}$ As our paper is only about
Correspondence: Mia P Kösters Department of Epidemiology and Health Promotion, Public Health Service of Amsterdam, PO Box 2200, 1000 CE, Amsterdam, The Netherlands Tel +3I 62255543 I

Email mkosters@ggd.amsterdam.nl 
the design of the study, we did not present any findings on effectiveness as this was impossible at the time.

\section{Discussion}

6. In the section "Prevention" ( $p$ 1422) the authors refer to the program we evaluated, ie, 'FRIENDS for Life'. Since we did not develop the 'FRIENDS for Life' program we believe the authors should refer to the original program description, published in Australia in 2004 by PM Barrett. ${ }^{3}$

We hope these comments are helpful and are looking forward to your reply.

\section{Disclosure}

The authors report no conflicts of interest in this communication.

\section{References}

1. Lima NN, do Nascimento VB, de Carvalho SM, et al. Childhood depression: a systematic review. Neuropsychiatr Dis Treat. 2013;9: $1417-1425$.

2. Kösters MP, Chinapaw MJ, Zwaanswijk M, van der Wal MF, Utens EM, Koot HM. Study design of 'FRIENDS for Life': process and effect evaluation of an indicated school-based prevention programme for childhood anxiety and depression. BMC Public Health. 2012;12:86.

3. Barrett PM. (2004a). FRIENDS for Life: Group leader's manual for children. Australia: Australian Academic Press. Barrett, P. M. (2004b). FRIENDS for Life: Workbook for children. Australia: Australian Academic Press. 


\section{Authors' reply}

\author{
Nádia Nara Rolim Lima' \\ Vânia Barbosa do Nascimento' \\ Sionara Melo Figueiredo de Carvalho' \\ Luiz Carlos de Abreu' ${ }^{1,3}$ \\ Modesto Leite Rolim Neto² \\ Aline Quental Brasil2 \\ Francisco Telésforo Celestino Junior ${ }^{2}$ \\ Gislene Farias de Oliveira ${ }^{2}$ \\ Alberto Olavo Advíncula Reis ${ }^{3}$
}

'Programa de Pós-graduação em Ciências da Saúde, Faculdade de Medicina do ABC, Santo André, São Paulo, Brazil; ${ }^{2}$ Departamento de Medicina, Universidade Federal do Ceará, UFC, Barbalha, Ceará, Brazil; ${ }^{3}$ Departamento de Saúde Materno Infantil, Faculdade de Saúde Pública, Universidade de São Paulo, São Paulo, Brazil

Correspondence: Luiz Carlos de Abreu

Faculdade de Medicina do ABC, Laboratório de Delineamento de Estudos e Escrita Científica, Faculdade de Medicina do ABC,

Av Príncipe de Gales, 82I, 09060-650, Santo André, São Paulo, Brazil

Tel +55 II 49935400

Fax +55 ।| 49937256

Email luiz.abreu@fmabc.br

\section{Dear editor}

We recently published a systematic review ${ }^{1}$ in Neuropsychiatric

Disease and Treatment which referred to a study published in BMC Public Health by Kösters et al. ${ }^{2}$ The aforementioned authors report that our review contains certain allegedly erroneous statements in referral to their paper. Considering this, we would appreciate the opportunity to comment/ respond to what was said by Kösters et al on behalf of all co-authors regarding our study. We opted to respond to what was said following Kösters et al's line of reasoning.

\section{Introduction}

1. We agree with the authors that their study described the study design and not the results. Nonetheless, while mentioning in our review "However, cases of depression have increased not only among adults, but also among children"1 ( $p$ 1417), we had the intention, based on Lima et al's referenced statement that "Anxiety disorders and depression are highly prevalent in children"2 ( 1 2; "Background" section) and on other sources, of deepening the World Health Organization's estimation that, by the year 2021, depression will be the second largest cause of the global disease burden. ${ }^{3}$ We highlight that the "Background" section is an integral part of their study, which allowed us to refer to this section as belonging to their study. Moreover, it was never said in our review that this piece of information resembled Kösters et al's results in any form.

2. The authors question the fact that we referred to their study in the sentence "In the short-term, depressive disorders might be a source of psychological suffering for these children, whereas in the long-term they can compromise social, cognitive, and emotional aspects of child development, $[\ldots]$ becoming an important predictor of psychopathologies in adulthood"1 (p 1418). In fact, we agree with the authors that the results of their paper bring no inference regarding predictors of psychopathology in adulthood, and it was never our intention to imply this conclusion by referencing their study.

However, in Kösters et al's paper, the "Background" section, referencing Beesdo et al ${ }^{4}$ and Roza et al, ${ }^{5}$ mentions that "Anxiety and depression are not only associated with limitations in children's current functioning (eg, poor social relations and academic performance, low selfesteem) $[\ldots]$, these disorders can also negatively affect children's emotional and social long term development. For example, childhood anxiety and depression are important predictors of psychopathology in adulthood"2 (p 2). Again, we highlight that the "Background" section is an integral part of Kösters et al's study, which allowed us to refer to this section as belonging to their study as well. Moreover, it was never said in our review that this piece of information resembled their results.

3. We acknowledge that the author's study ${ }^{2}$ was included in our review as an experimental study, whilst the nonrandomized design used qualified the study as quasi-experimental, which implies a cognitive bias, and, therefore, a limitation of our study.

4. We agree with the authors that their study's sample was not definitive at the time that they published the paper. However, considering that "at least 20 primary schools" 2 is not a determined sample to be referred to, as well as the fact that it was not feasible to fully mention the sample selection bias of each of the referred studies on our table, in this case we opted to mention only the sample that was confirmed at the moment of publication of the author's study.

5. Table 1 (p 1420) of our review mentions that " "FRIENDS for Life' is effective as an indicated school-based prevention program for children with early or mild signs of anxiety or depression". ${ }^{1}$ Despite the fact that the author's paper did not present any findings on the effectiveness of 'FRIENDS for Life' in their "Results" section, the authors mentioned in the "Background" section of their study that "FRIENDS 
for Life' is a programme that can be used for the prevention and treatment of anxiety and depression in children [...]. This cognitive-behavioral programme teaches children skills to cope more effectively with feelings of anxiety and depression and builds emotional resilience, problemsolving abilities and self-confidence" ${ }^{\prime 2}(\mathrm{p} 2)$.

\section{Discussion}

6. The authors, despite not having developed the 'FRIENDS for Life' program, in the "Intervention" sub-section of their "Methods" section thoroughly describe the aforementioned program; all pieces of information regarding the program's description referred to in our study were based on Kösters et al's description of the program. ${ }^{2}$ In addition, although we agree with the authors that Barrett's program description ${ }^{6}$ would be a far more thorough source, it would not be possible for us to refer to the original program description considering that, as mentioned in our "Methods" section, we performed a systematic review of articles, and Barrett's publication did not appear as a valid reference while applying our search strategy and eligibility criteria.

Finally, we would like to demonstrate our appreciation for Kösters et al's comments regarding our study, as they have effectively contributed to further deepen the raison d'être of our review. We hope our response has proved to be useful.

\section{Disclosure}

The authors report no conflicts of interest in this communication.

\section{References}

1. Lima NN, do Nascimento VB, de Carvalho SM, et al. Childhood depression: a systematic review. Neuropsychiatr Dis Treat. 2013;9: $1417-1425$.

2. Kösters MP, Chinapaw MJ, Zwaanswijk M, van der Wal MF, Utens EM, Koot HM. Study design of 'FRIENDS for Life': process and effect evaluation of an indicated school-based prevention programme for childhood anxiety and depression. BMC Public Health. 2012;12:86.

3. World Health Organization. The World Health Report 2001 - Mental Health: New Understanding, New Hope. Geneva: World Health Organization; 2001. Available from: http://www.who.int/whr/2001/en/. Accessed February 20, 2014.

4. Beesdo K, Bittner A, Pine DS, et al. Incidence of social anxiety disorder and the consistent risk for secondary depression in the first three decades of life. Arch Gen Psychiatry. 2007;64:903-912.

5. Roza SJ, Hofstra MB, van der Ende J, Verhulst FC. Stable prediction of mood and anxiety disorders based on behavioral and emotional problems in childhood: a 14-year follow-up during childhood, adolescence, and young adulthood. Am J Psychiatry. 2003;160(12):2116-2121.

6. Barrett PM. FRIENDS for Life: Group Leader's Manual for Children. Bowen Hills: Australian Academic Press; 2004.
Neuropsychiatric Disease and Treatment

\section{Publish your work in this journal}

Neuropsychiatric Disease and Treatment is an international, peerreviewed journal of clinical therapeutics and pharmacology focusing on concise rapid reporting of clinical or pre-clinical studies on a range of neuropsychiatric and neurological disorders. This journal is indexed on PubMed Central, the 'PsycINFO' database and CAS.
Dovepress

The manuscript management system is completely online and includes a very quick and fair peer-review system, which is all easy to use. Visit http://www.dovepress.com/testimonials.php to read real quotes from published authors. 